Article

\title{
Pre-Disaster Retrofit Decisions for Sustainable Transportation Systems in Urban Areas
}

\author{
Yingliang Zhou ${ }^{1} \mathbb{D}$, Qiwei Jiang ${ }^{2}$ and Jin Qin ${ }^{1, * \mathbb{C}}$ \\ 1 School of Traffic and Transportation Engineering, Central South University, No. 22 South Section Shaoshan \\ Road, Changsha 410075, China \\ 2 School of Civil Engineering, Central South University, No. 22 South Section Shaoshan Road, \\ Changsha 410075, China \\ * Correspondence: qinjin@csu.edu.cn
}

Received: 24 June 2019; Accepted: 25 July 2019; Published: 26 July 2019

\begin{abstract}
A transportation system is an important material base for implementing timely rescue and emergency evacuation after disasters in urban areas. In order to reduce disaster risks and develop sustainable transportation systems, it is important to improve their resilience and ensure their reliability. This paper mainly studies pre-disaster retrofit decisions for sustainable transportation systems in urban areas. As the optimization goal, pre-disaster retrofit costs and post-disaster restoration costs under constraints of post-disaster system connectivity, travel time reliability, and post-disaster link capacity are taken into account to construct a bi-level stochastic programming model. A method based on the simulated annealing algorithm and Frank-Wolfe algorithm is used to solve the problem. The case study shows that the calculation is quick, and the result is reasonable. The study result proves that the method proposed in this paper can provide an effective solution to such problems.
\end{abstract}

Keywords: sustainable transportation systems; pre-disaster retrofit; disaster risk reduction; bi-level stochastic programming model; simulated annealing algorithm

\section{Introduction}

Disasters happen accidentally or naturally and can seriously threaten human life and critically hinder social economic development [1]. According to the United Nations Office for Disaster Risk Reduction (UNISDR), from 2005 to 2014, disasters caused an estimated \$1439 billion in damage, and about 1696 million people were affected, and 729,100 people were killed. China, US, Philippines, India, and Indonesia were the top five countries with the most disasters over a 10-year period [2].

Once disasters occur, victims need to be rescued and resettled, and water and food should be transported to disaster areas [3]. Transportation systems play a vital role in life assistance and post-disaster recovery [4-6]. In the 2013 China earthquake, $4428 \mathrm{~km}$ of road was damaged, including $541 \mathrm{~km}$ of national and provincial trunk highways, $3887 \mathrm{~km}$ of rural road, and 21 bridges $[5,7,8]$. Damage to key infrastructure such as roads, bridges, and tunnels may lead to functional loss of transportation systems, which seriously hinders effective disaster risk management.

Disaster risk management through transportation systems mainly includes three parts: Crowd evacuation, material transportation, and post-disaster rescue. First, the focus on crowd evacuation is to determine evacuation demands, based on basic data such as disaster impact and land use; to determine evacuation areas by estimating disaster areas and risk magnitude; to estimate the number of evacuations, especially those using public transport; and to determine the locations of evacuation origins and destinations, as well as routes. Second, for transporting materials, a transportation plan needs to be determined by having prior comprehensive information such as disaster degree, the situation of the victims, the presence of secondary disasters, and system connectivity and capacities. 
The goal is to transport basic materials to the disaster area at the fastest speed. Finally, post-disaster rescue mainly includes treating and transferring wounded people and determining the personnel, equipment, and vehicles needed for rescue based on the degree of urgency. In order to deploy rescue forces rationally, it is important to integrate resources effectively and provide relevant organizations with the optimal rescue route in disaster areas.

Therefore, sustainable transportation systems can benefit greatly from urban disaster risk reduction, which can be weighed by their resilience. Originally, resiliency referred to the ability to withstand the effects of a disaster such as an earthquake with respect to observations during the recovery. The first wide use of the term "resilience" in engineering science appeared in 1858, to describe the strength and ductility of steel beams. In engineering science, a resilient steel beam survives the application of a force by resisting it with strength and rigidity and absorbing it with ductility. In disaster risk reduction, the strength is in the ability to devise means of resisting disaster and maintaining integrity, while the ductility lies in the ability to adapt to circumstances produced by disasters in order to lessen their impact $[9,10]$. "Resilience" is currently used in disaster risk reduction and was given a good definition by UNISDR as "the ability of a system, community or society exposed to hazards to resist, absorb, accommodate to and recover from the effects of a hazard in a timely and efficient manner, including through the preservation and restoration of its essential basic structures and functions" [11].

By analogy to the transportation field, this paper proposes that resilience is the ability of sustainable transportation systems to engage in emergency response, disaster risk mitigation, and post-disaster recovery, which reflects the ability to resist [8], respond to, and recover from disasters. The main components of resilience that contribute to effective risk management through transportation systems are resistance ability, emergency response ability, and recovery ability. The resistance ability drives transportation systems to withstand disasters to the maximum extent and minimizes the disaster impact on their post-disaster states especially about link damage. The emergency response ability is mainly weighed by emergency response time of transportation systems. For effective risk management, it is important to reduce emergency response time as much as possible and transfer personnel and transport material at the fastest speed. The recovery ability mainly reflects on the process of post-disaster rescue and link restoration of transportation systems.

In urban areas, transportation systems face multiple disaster risks. Disasters happen suddenly, generally with no or few signs before they occur. It is hard to estimate their specific time, scope of impact, and development trend [12,13]. The damage to infrastructures of transportation systems caused by disasters can have an enormous impact on system connectivity, travel time, and link capacity [14-17]. To improve the accessibility and transport quality of transportation systems in disasters, this paper suggests that it is significant to retrofit transportation systems in advance. It should be pointed out that a transportation system retrofit is not the same as retrofitting all links in the system. It is necessary to select links [18] of transportation systems for pre-disaster retrofit in order to cope with various disaster scenarios that could occur in disaster risk areas. In a word, for urban disaster risk reduction $[19,20]$ and sustainable development of transportation systems, this paper studies pre-disaster retrofit decisions for transportation systems in urban areas.

Pre-disaster retrofitting and post-disaster restoration generally entail huge economic costs. The probability of extremely serious disasters is extremely low, and retrofitting each link to the highest degree to withstand such disasters would result in unbearable costs. According to our study, pre-disaster retrofitting can decrease future economic losses from social cost and repair/restoration cost during the remaining service life of the transportation system [21]. As well as the limited retrofit budget, how to allocate the budget reasonably [22] to maximize the retrofit effect is the key issue.

This paper presents three key innovations. First, retrofit decision variables in most existing research are binary variables, only considering whether to retrofit or not. However, in reality, due to factors such as cost, it is not realistic to retrofit each link to the highest degree. According to the relevant engineering operation standards, this paper proposes that links can be retrofitted to different degrees as different retrofit levels. Second, in most existing research, post-disaster link capacity is 
generally ignored. Post-disaster link capacity is taken into account in this paper, and the damage extent is introduced as well. In addition to two post-disaster link states of connection and disconnection, this paper adds a new state of connection with capacity reduction. Finally, this paper proposes a method to determine the pre-disaster retrofit level of each link for a transportation system with a limited retrofit budget. To minimize the total costs for retrofitting and maintaining links from a mathematical point of view, system connectivity, travel time reliability, and link capacity are taken into account at the same time.

To obtain the maximum retrofit effect with the minimum cost, it is important to develop a sustainable transportation system for post-disaster rescue, evacuation, material transportation, and recovery. As well as urban disaster risk reduction acting on transportation systems, pre-disaster retrofit decision plans are extremely necessary. The research can help policymakers to analyze and optimize their decision-making with a comprehensive and systematic view, as well as help guide the restoration and reconstruction of transportation systems in urban areas to create greater socioeconomic benefits.

The rest of this paper is organized as follows: Section 2 presents a comprehensive review of the related literature. Section 3 presents assumptions of the problem and the proposed mathematical model. The proposed solving method is shown in Section 4. The case of a midsize city in China with disaster risks is described in Section 5 to validate the model and solution. Section 6 provides a conclusion and future directions.

\section{Literature Review}

There are quantities of studies about road restoration. However, research on pre-disaster retrofit of transportation systems has been carried out in recent years. In order to grasp the research progress, this paper sorts out the existing literatures.

\subsection{The Goals of Pre-Disaster Retrofit}

Some studies $[6,18]$ contributed to maximize post-disaster network accessibility for all locations in the area during the restoration process. Liu and Fan et al. [12] studied on the improvement of resilience and robustness of transportation systems over multiple highway bridges, minimizing future seismic losses at the same time. The retrofit goal of Du and Peeta [13] was to enhance network survivability and minimize the expected post-disaster response time. Chu and Chen [14] proposed a two-stage stochastic programming model to identify an optimal protection plan to maximize connectivity reliability for highway networks. Some scholars $[21,23,24]$ found that seismic retrofitting could reduce total future economic losses from social cost and repair/restoration cost during the service life of bridges. Peeta and Salman et al. [25] did a study on a pre-disaster planning problem with the goal of maximizing post-disaster network connectivity and minimizing network travel time. Yan and Hong et al. [26] presented to minimize the expected railway system service loss subject to earthquake hazard. Rokneddin, Ghosh, and Dueñas-Osorio [27] evaluated the seismic reliability of aging bridges in highway networks via a time-dependent seismic fragility analysis of typical bridge classes. The study of Kim [28] can be useful to assist in prioritizing components of infrastructure systems for seismic retrofitting to enhance their post-earthquake functionality. Dong, Frangopol, and Saydam [29] were devoted to determine the optimum timing of retrofit actions for bridges within a network. Network efficiency [30] was considered to be improved especially within post-disaster transportation networks.

In summary, minimizing future seismic losses was one of the main retrofit goals of the existing studies, while the focuses were around service losses, economic losses, and social losses. To enhance the reliability concerning connectivity, capacity, travel time, and response time of networks was also important, and scholars generally optimized two of them at most. The researches studied post-disaster transportation system performance as well, mainly contributing on accessibility, functionality, survivability, and efficiency. 


\subsection{The Factors Considered in Retrofit Plan}

The limited resources and budget were the main factors considered in studies while making a retrofit plan $[6,12,13,26,28,29]$ because of the well-known reality. The user-equilibrium principle [23] could not be neglected as well, while traffic congestion and travelers' trip-making or route-choice behavior [31] were supposed to be taken into consideration. The suddenness and unpredictability of disasters made the uncertainty of future disaster $[23,29]$ as factors that cannot be ignored during the research process. Nagae $T$ and Fujihara $T$ et al. [25] researched on retrofitting transportation facilities of urban road network under multiple earthquake risks under the condition that the realistic damage patterns on the road network and their occurrence probabilities were known beforehand. Peeta $S$ and Salman F S et al. [25] did research on strengthening a highway network whose links are subject to random failures due to a disaster under the condition that the link failure probabilities were known beforehand. Some studies contributed to determine the retrofit priorities of infrastructures, considering the structural vulnerability and significance $[6,28,29]$ of key infrastructures within the transportation systems. Network-level importance [27] and system-level performance [28] were also considered by some studies.

\subsection{The Method Applied in the Literature}

A two-stage stochastic programming model [12-14] was the most common way proposed by scholars with different objectives and constraints. Moreover, various algorithms were developed to solve the model. Someone developed an efficient algorithm by extending the L-shaped method using generalized Benders decomposition to handle the model [12]. A two-stage heuristic algorithm was proposed by $\mathrm{Du}$ and Peeta to solve the model efficiently [13].

A dynamic path based mathematical model was proposed by Tuzun Aksu D and Ozdamar L [6] to identify criticality of blockages. Yücel E and Salman F S et al. [18] presented a new dependency model to improve post-disaster network accessibility via strengthening the links of the network structurally to decrease link failure probability. An efficient tabu search algorithm was developed, and Istanbul under the risk of an earthquake was selected as the case to illustrate the study's usefulness. Two sets of bridge fragility curves [21] were used to simulate the seismic performance of the network before and after retrofitting, and the California Department of Transportation (Caltrans) Los Angeles area highway network was tested to illustrate the method. An efficient solution of a progressive hedging-based method was developed by Fan and Liu [23] to solve large-scale stochastic network optimization problems with equilibrium constraints. A genetic algorithm was used to solve the model and the Chinese railway system (CRS) was taken as an example [26]. Rokneddin, Ghosh, and Dueñas-Osorio [27] proposed an efficient algorithm based on finite-state Markov chain Monte Carlo simulations.

There are three key challenges of existing studies. First, retrofit decision variables in most existing studies are binary variables, only considering whether to conduct pre-disaster retrofitting or not. However, the probability of extremely serious disasters is extremely low, and retrofitting each link to the highest degree to withstand such disasters will result in unbearable costs. Second, most existing studies have few indicators for post-disaster states of transportation systems, and more indicators could be taken into account. Third, the assumptions in some studies could be considered more comprehensively. For instance, some studies assume that retrofitted links will be unaffected and non-retrofitted links will be destroyed after a disaster. The assumption might be unilateral, and there may be other possibilities.

Based on the existing research, this paper identifies several gaps. First, this paper proposes to subdivide retrofits into five levels: Non-retrofit, minor retrofit, medium retrofit, overhaul retrofit, and reconstruction [32,33], according to the relevant engineering operation standards. Non-retrofit is at level 0; minor retrofit is at level 1, mainly for maintaining and repairing parts of the links with minor damage; medium retrofit is at level 2, for maintaining general wear and partial damage; overhaul retrofit is at level 3, for comprehensive repair of large damage; reconstruction is at level 4, and reconstructed links will remain in good condition after a disaster. Second, this paper proposes minimizing the 
total cost for pre-disaster retrofitting and post-disaster link restoration. System connectivity, travel time reliability, and link capacity are also taken into account. Third, this paper proposes one more assumption: Links retrofitted at levels 1 to 3 will be damaged to different degrees but will still remain connective, with reduced post-disaster capacity.

\section{Assumptions and Models}

\subsection{Assumptions}

To formulate the proposed model, the following reasonable assumptions are made:

Assumption 1. The probability of disaster scenario occurrence is known prior.

Assumption 2. The set of links that are not affected by disasters is known, and those links need no retrofitting, while others are considered to be pre-disaster retrofitted.

Assumption 3. Non-retrofitted links will be destroyed by disasters and will not be passable. Retrofitted links will be damaged by disasters, retaining connectivity but with decreased capacity.

Assumption 4. The travel demands of the transportation system will vary after a disaster.

Assumption 5. Evacuation and rescue work after a disaster will be organized in an orderly way.

\subsection{Sets and Indices}

For a transportation system $G(N, A)$ :

$N$ is the set of nodes $\{1, \ldots \ldots, n\}$;

$A_{1}$ is the set of links unaffected by the disaster;

$A_{2}$ is the set of links subjected to the disaster;

$A$ is the set of links $\{1, \ldots \ldots, a\}, A=A_{1} \cup A_{2}$;

$W$ is the set of origin-destination $(O D)$ pairs $[i, j], i, j \in N$;

$T_{0}$ is the total impedance of the transportation system before a disaster;

$\Omega$ is the set of disaster scenarios;

$\omega$ is the disaster scenarios that transportation systems might face, $\omega \in \Omega$;

$A_{\omega}$ is the set of connective paths under disaster scenario $\omega, \omega \in \Omega$.

\subsection{Mathematical Model}

A bi-level stochastic programming model is formulated, and explanations are presented in this section.

The model is formulated in two levels; the upper level is for pre-disaster decision-making about transportation systems, and the lower level is a system optimum model. The connection between the two levels is that the impedance of each link in the upper level is obtained from the lower level.

\subsubsection{Upper Level of the Model}

The upper level of this model is aimed at minimizing the total cost of retrofitting and maintaining links, which considers constraints of budget, connectivity, travel time reliability, capacity, and variable values.

The decision-making model regards minimizing total cost as an optimization goal. In Equation (1), the total cost actually consists of two parts: Pre-disaster retrofit costs and expected post-disaster emergency restoration costs. Post-disaster emergency restoration is mainly aimed at the destroyed links to ensure the connectivity of the post-disaster transportation system.

$$
\min S=\sum_{a \in A_{2}} \sigma_{y_{a}} \cdot l_{a}+\sum_{\omega \in \Omega} \sum_{a \in A_{2}} P_{\omega} \cdot \theta_{a}(\omega) \cdot \tau_{a} \cdot l_{a} \cdot\left(1-\pi\left(\omega_{a}, y_{a}\right)\right)
$$


where $y_{a}$ is the retrofit decision variable of link $a$.

$$
y_{a}=\left\{\begin{array}{c}
n, n=0,1,2,3,4, a \in A_{2} \\
0, a \in A_{1}
\end{array}\right.
$$

In Equation (2), $n$ is retrofit levels 0-4, corresponding to non-retrofit, minor retrofit, medium retrofit, overhaul retrofit, and reconstruction, respectively; $\sigma_{y_{a}}$ is the retrofit cost of unit length, with $y_{a}$ as the retrofit decision; $l_{a}$ is the length of link $a ; P_{\omega}$ is the probability of occurrence of disaster scenario $\omega, \sum_{\omega \in \Omega} P_{\omega}=1$; and $\theta_{a}(\omega)$ is the probability of damage [13] to link $a$ under disaster scenario $\omega$.

$$
\theta_{a}(\omega)=\zeta_{a}(\omega)-\lambda \cdot\left(\zeta_{a}(\omega)-\varphi_{a}(\omega)\right)
$$

In Equation (3), $\varphi_{a}(\omega)$ and $\zeta_{a}(\omega)$ represent the probability of damage to link $a$ under disaster scenario $\omega$, which are after reconstruction $\left(y_{a}=4\right)$ and non-retrofitted $\left(y_{a}=0\right)$, respectively.

$\lambda$ is the piecewise function of the variable $y_{a}$ :

$$
\lambda=\left\{\begin{array}{c}
0, y_{a}=0 \\
0.1, y_{a}=1 \\
0.5, y_{a}=2 \\
0.7, y_{a}=3 \\
1, y_{a}=4
\end{array}\right.
$$

$\tau_{a}$ is the restoration cost of unit length; $\omega_{a}$ is the risk state of link $a$ under disaster scenario $\omega: 1$ if link $a$ is not affected in disaster scenario $\omega$, otherwise 0 ; and $\pi\left(\omega_{a}, y_{a}\right)$ is the post-disaster connectivity state relative to retrofit decision $y_{a}$ and risk state $\omega_{a}$ under disaster scenario $\omega: 1$ if link $a$ retains connectivity, otherwise 0 .

$$
\pi\left(\omega_{a}, y_{a}\right)=\left\{\begin{array}{c}
1, \forall a \in A_{1} \text { or } \forall a \in A_{2}, y_{a} \neq 0 \\
0, \forall a \in A_{2}
\end{array}\right.
$$

It is necessary to satisfy budget constraints when making pre-disaster retrofit decisions. That is, the retrofit costs are not supposed to exceed the budget ceiling.

$$
\sum_{a \in A_{2}} \sigma_{y_{a}} \cdot l_{a} \leq \varepsilon
$$

where $\varepsilon$ is the budget ceiling of the pre-disaster retrofit.

System connectivity is an important goal of sustainable transportation systems. To ensure system connectivity, there should be at least one valid path between any $O D$ pair. That is, pre-disaster retrofit decision plan $\bar{Y}$ should ensure that there is at least one path $k$ on which post-disaster connectivity state $\pi\left(\omega_{a}, y_{a}\right)$ of all links is 1 between any $O D$ pair $[i, j]$ under disaster scenario $\omega[15]$.

$$
\sum_{k \in K_{i j}} \prod_{a \in A_{\omega}} \pi\left(\omega_{a}, y_{a}\right) \cdot \delta_{i j}^{a k} \geq 1 \quad \forall[i, j] \in W, \omega \in \Omega
$$

$K_{i j}$ is the set of connective paths between $O D$ pairs $[i, j] ; \delta_{i j}^{a k}$ is 1 if link $a$ is on path $k$ connecting the $O D$ pair $[i, j]$, otherwise 0 .

This paper introduces a time reliability coefficient $\gamma_{t}$ [16], whose value depends on the required retrofit effect. In order to ensure travel time reliability of transportation systems after disasters, pre-disaster retrofit decision plan $\bar{Y}$ should ensure that the ratio of emergency travel time after 
retrofitting under disaster scenario $\omega$ to normal travel time [3] between any OD pair $[i, j]$ should not exceed a coefficient $\gamma_{t}$.

$$
\sum_{k \in K_{i j}} \sum_{a \in A_{\omega}} t_{a}\left(x_{a}, C\left(\omega_{a}, y_{a}\right)\right) \cdot \delta_{i j}^{a k} \leq \gamma_{t} \cdot \sum_{k \in K_{i j}} \sum_{a \in A_{\omega}} t_{a}\left(x_{a}, c_{a}\right) \cdot \delta_{i j}^{a k} \forall[i, j] \in W, \omega \in \Omega
$$

where $c_{a}$ is the capacity of link $a ; t_{a}\left(x_{a}, c_{a}\right)$ is the traffic impedance of link $a$; and $C\left(\omega_{a}, y_{a}\right)$ is the post-disaster capacity $[34,35]$ of link $a$. $\mathcal{c}_{a} \cdot(1-\beta)$ if link $a$ is subject to disaster scenario $\omega\left(\forall a \in A_{1}\right)$ and its damage extent is $\beta, c_{a}$, otherwise $\left(\forall a \in A_{2}\right)$.

$$
C\left(\omega_{a}, y_{a}\right)=\left\{\begin{array}{c}
c_{a} \cdot(1-\beta), \forall a \in A_{2} \\
c_{a}, \forall a \in A_{1}
\end{array}\right.
$$

where $\beta$ is the damage extent [36] of link $a$ after five kinds of retrofit projects, which can be obtained according to prior experience [37]. Table 1 presents the situations of links relative to five retrofit projects.

Table 1. Damage state of links under disaster scenarios after five retrofit projects.

\begin{tabular}{cccccc}
\hline Retrofit Project & Non-Retrofit & Minor Retrofit & Medium Retrofit & Overhaul Retrofit & Reconstruction \\
\hline $\begin{array}{c}\text { Retrofit level } \\
\text { Link damage state }\end{array}$ & 0 & 1 & 2 & 3 & 4 \\
Link damage & Destroyed & Serious damage & Medium damage & Slight damage & No impact \\
extent $\beta$ & 1 & 0.8 & 0.65 & 0.3 & 0 \\
\hline
\end{tabular}

In order to ensure that the links within the post-disaster transportation system have certain capacity, the traffic flow of the link cannot exceed its post-disaster capacity [23,36].

$$
x_{a} \leq C\left(\omega_{a}, y_{a}\right) a \in A_{\omega} .
$$

The retrofit is divided into five levels:

$$
y_{a}=n \quad a \in A_{2}, n=0,1,2,3,4 .
$$

In summary, Equation (1) shows the objective function in the upper-level model, which minimizes the pre-disaster retrofit cost and the expected post-disaster emergency restoration cost. Constraint (6) shows that the retrofit cost is not supposed to exceed budget constraints because of limited construction funds. To ensure system connectivity [15] under disaster scenario $\omega$, constraint (7) shows that it is necessary for at least one path to exist between $O D$ pair $[i, j]$ after being retrofitted as optimization plan $\bar{Y}$. To ensure travel time reliability of a transportation system after being retrofitted as optimization plan $\bar{Y}$ under disaster scenario $\omega$, constraint (8) shows that the ratio of emergency travel time to normal travel time between $O D$ pairs should not exceed a coefficient $\gamma_{t}[16]$, whose value depends on the required retrofit effect. Constraint (10) explains that traffic flow of each link should not exceed post-disaster capacity [23,36]. Constraint (11) represents nonnegative integer variables of the model, which range from 0 to 4 .

\subsubsection{Lower Level of the Model}

A transportation system may face multiple possible disaster scenarios such that its post-disaster system structures are different with $|\Omega|$ kind of fixed demand.

$$
\min T_{\omega}=\sum_{a \in A_{\omega}} x_{a} \cdot t_{a}\left(x_{a}, C\left(\omega_{a}, y_{a}\right)\right) \quad \omega \in \Omega
$$




$$
\begin{gathered}
\sum_{k \in K_{i j}} f_{i j}^{k}=\mu_{\omega} \cdot q_{i j}^{\text {s.t. }} \quad \forall i, j \in N, \omega \in \Omega \\
f_{i j}^{k} \geq 0 \quad \forall i, j \in N, \forall k \in K_{i j} \\
x_{a}=\sum_{[i, j] \in W} f_{i j}^{k} \cdot \delta_{i j}^{a k} \quad \forall i, j \in N, \forall a \in A_{\omega}
\end{gathered}
$$

where $T_{\omega}$ is the total impedance of the transportation system under disaster scenario $\omega ; \mu_{\omega}$ is a travel demand matrix multiplier [16,36] under disaster scenario $\omega ; q_{i j}$ is the traffic demand between $O D$ pair $[i, j]$; and $f_{i j}^{k}$ is the flow of path $k\left(k \in K_{i j}\right)$ between $O D$ pair $[i, j]$.

The lower level of this model is a system optimum model that describes the user's behavior of avoiding risk and choosing routes in a post-disaster urban area. As with previous assumptions, post-disaster evacuation and rescue work will be well organized; that is, users (travelers or drivers) in this transportation system will be subject to government allocation. The system will omit congestion effects and link impedances will not vary with traffic flow. Users will choose the minimum impedance path between two nodes, that is, traffic flow will be allocated to the minimum impedance path between each $O D$ pair. Therefore, the "all in all" algorithm can be used to solve the lower-level model.

\section{Solution Methodology}

This kind of problem is an NP-hard problem. It is difficult to solve by accurate algorithms and commercial software. A solution based on the simulated annealing algorithm and Frank-Wolfe algorithm is designed to solve the problem. The simulated annealing algorithm has the characteristics of flexible use, convenient description, easy implementation, and high computational efficiency. Therefore, this algorithm is chosen to solve the upper level of the model, while the Frank-Wolfe algorithm is for the lower.

The key of the simulated annealing algorithm is neighborhood constructions; in this paper, they are constructed by transforming the retrofit levels of 1-3 links. As shown in Figures 1 and 2, retrofit levels of two links between nodes 1, 4 and nodes 5, 6 are changed while others are unchanged.

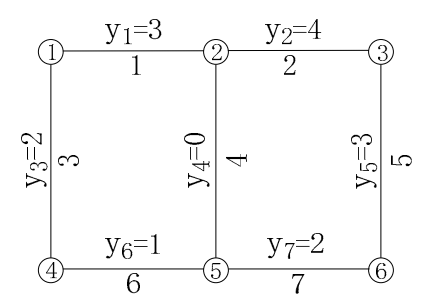

Figure 1. Current solution $\bar{Y}$.

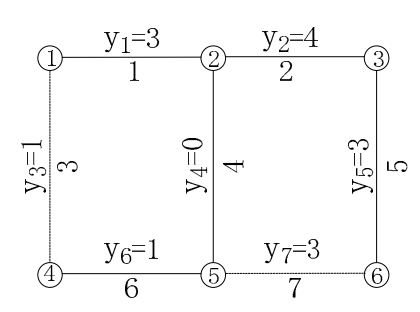

Figure 2. Neighborhood solution $\overline{Y_{1}}$ based on 2-exchange.

The Figure 3 is a flow chart to explain the solution. 


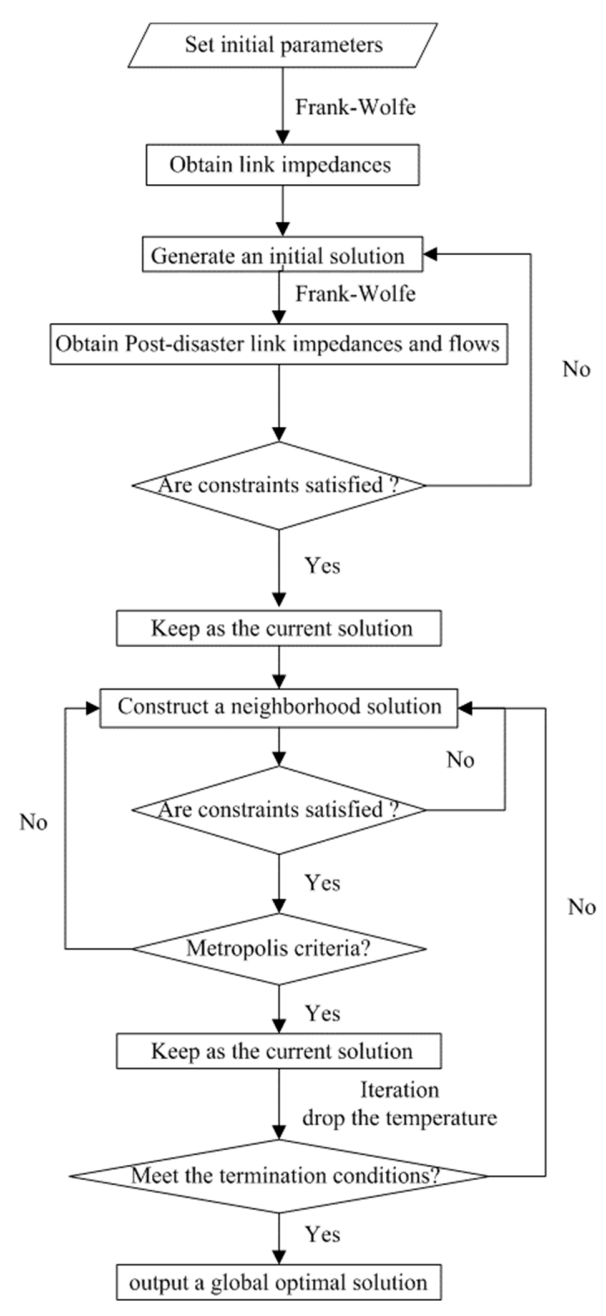

Figure 3. A flow chart of the solution.

Detailed steps of the solution [38-41] are as follows:

Step 1. Set initial values of parameters.

Set the initial temperature $t_{0}$, temperature drop ratio $\lambda$, and terminal temperature $t_{f}$. Set $L$ as the iteration limit number at the same temperature, and set iteration number $l=1$ at the current temperature. To obtain the impedance $t_{a}\left(x_{a}, c_{a}\right)$ of each link, the Frank-Wolfe algorithm [20] is used for distributing traffic flows in an initial transportation system.

Step 2. Determine the current solution $\overline{Y_{0}}$ and the objective function $S_{0}$.

(1) Generate an initial solution of the model that represents an initial proposal $\bar{Y}$ of pre-disaster retrofit.

(2) $\bar{Y}$ is used to determine post-disaster transportation systems with the number of $|\Omega|$. Thus, connectivity states and capacities of links under various disaster scenarios can be obtained. Impedance $t_{a}\left(x_{a}, C\left(\omega_{a}, y_{a}\right)\right)$ and flow $x_{a}$ of each link of the post-disaster transportation system can be obtained in a way similar to step 1 .

(3) Judge the feasibility of $\bar{Y}$. If all the constraints in this model are satisfied, set the current solution $\overline{Y_{0}}=\bar{Y}$, and obtain an initial objective function $S_{0}$ in the upper-level model. Otherwise, repeat step 2.

Step 3. Construct a neighborhood solution $\overline{Y_{1}}$. 
(1) According to the above method of neighborhood construction, a neighborhood solution $\overline{Y_{1}}$ of the current solution $\overline{Y_{0}}$ is obtained.

(2) Distribute traffic flows in the post-disaster transportation system, and judge the feasibility of $\overline{Y_{1}}$ in a way similar to step 2 . If all the constraints are satisfied, go to step 4. Otherwise, repeat step 3.

Step 4. Calculate objective function $S_{1}$ of $\overline{Y_{1}}$.

Step 5. Judge whether to accept the neighborhood solution as the current solution according to metropolis criteria.

Calculate $\Delta S=S_{1}-S_{0}$. If $\Delta S \leq 0$, accept $\overline{Y_{0}}=\overline{Y_{1}}, S_{0}=S_{1}$. If $\Delta S>0$, set acceptance probability of the worst solution as $p(\cdot)=\exp \left(-\Delta S / t_{i}\right)$ and generate a random value $r$ from the interval $(0,1)$. If $r<p(\cdot)$, accept $\overline{Y_{0}}=\overline{Y_{1}}, S_{0}=S_{1}$. Otherwise, the neighborhood solution is not accepted as the current solution.

Step 6. Iterate at the same temperature.

Set $l=l+1$. If $l \geq L$, go to step 7 . Otherwise, return to step 3 .

Step 7. Drop the temperature.

Adjust current temperature to $t_{i+1}=\lambda \cdot t_{i}$ according to the rules of dropping temperature.

Step 8. Judge the convergence of the algorithm.

If current temperature $t_{i+1}<t_{f}$, terminate the algorithm and output a global optimal solution $\overline{Y_{0}}$ and the objective function $S_{0}$. Otherwise, reset $l=1$ and return to step 3 .

Note that parameter $p$ can be appropriately adjusted within a reasonable range in algorithm solving according to concrete situations.

\section{Application}

The proposed model is applied to the transportation system of a midsize city in China (Figure 4).

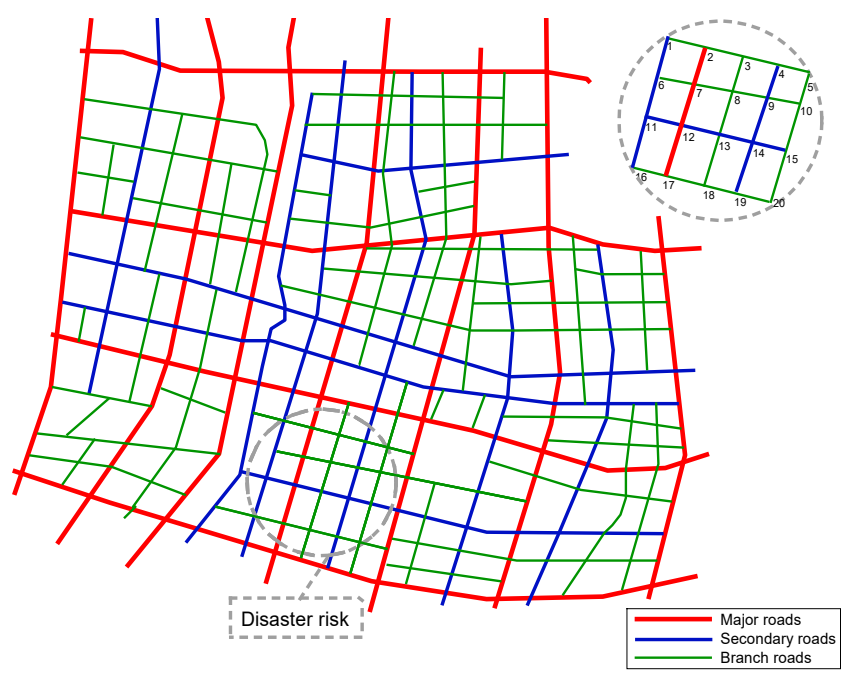

Figure 4. Transportation system of a midsize city in China.

The travel demand between $O D$ pairs in disaster risk areas of the city is presented in Table 2. It shows that the travel demand between nodes is not symmetrical, that is, the traffic flow between two nodes has a main direction. 
Table 2. Travel demand between origin-destination (OD) pairs.

\begin{tabular}{ccccccccccccccccccccc}
\hline $\boldsymbol{N}$ & $\mathbf{1}$ & $\mathbf{2}$ & $\mathbf{3}$ & $\mathbf{4}$ & $\mathbf{5}$ & $\mathbf{6}$ & $\mathbf{7}$ & $\mathbf{8}$ & $\mathbf{9}$ & $\mathbf{1 0}$ & $\mathbf{1 1}$ & $\mathbf{1 2}$ & $\mathbf{1 3}$ & $\mathbf{1 4}$ & $\mathbf{1 5}$ & $\mathbf{1 6}$ & $\mathbf{1 7}$ & $\mathbf{1 8}$ & $\mathbf{1 9}$ & $\mathbf{2 0}$ \\
\hline 1 & 0 & 10 & 23 & 8 & 23 & 27 & 11 & 29 & 16 & 17 & 22 & 24 & 22 & 29 & 30 & 17 & 25 & 19 & 16 & 22 \\
2 & 13 & 0 & 49 & 13 & 26 & 11 & 21 & 28 & 33 & 15 & 24 & 22 & 27 & 29 & 33 & 29 & 21 & 21 & 24 & 32 \\
3 & 24 & 51 & 0 & 17 & 32 & 19 & 22 & 18 & 37 & 23 & 10 & 23 & 8 & 23 & 27 & 11 & 29 & 16 & 17 & 34 \\
4 & 10 & 22 & 14 & 0 & 23 & 23 & 14 & 17 & 26 & 16 & 20 & 43 & 13 & 26 & 11 & 21 & 28 & 33 & 15 & 13 \\
5 & 18 & 32 & 29 & 24 & 0 & 24 & 31 & 20 & 35 & 24 & 31 & 20 & 17 & 32 & 19 & 22 & 18 & 37 & 24 & 41 \\
6 & 25 & 11 & 13 & 27 & 23 & 0 & 28 & 25 & 24 & 15 & 22 & 14 & 20 & 23 & 23 & 14 & 17 & 26 & 10 & 22 \\
7 & 23 & 14 & 21 & 11 & 39 & 25 & 0 & 48 & 20 & 18 & 32 & 29 & 24 & 20 & 24 & 31 & 20 & 35 & 18 & 31 \\
8 & 17 & 26 & 14 & 14 & 26 & 11 & 43 & 0 & 48 & 25 & 11 & 13 & 27 & 23 & 19 & 28 & 25 & 24 & 15 & 27 \\
9 & 20 & 29 & 21 & 25 & 35 & 27 & 17 & 34 & 0 & 23 & 14 & 21 & 11 & 39 & 25 & 17 & 48 & 20 & 18 & 23 \\
10 & 15 & 17 & 20 & 13 & 23 & 28 & 23 & 24 & 11 & 0 & 17 & 26 & 14 & 14 & 26 & 11 & 43 & 24 & 48 & 14 \\
11 & 21 & 26 & 13 & 20 & 49 & 13 & 21 & 11 & 21 & 29 & 0 & 23 & 23 & 14 & 17 & 26 & 16 & 20 & 43 & 13 \\
12 & 26 & 24 & 24 & 51 & 30 & 17 & 32 & 19 & 22 & 28 & 24 & 0 & 17 & 32 & 19 & 22 & 18 & 37 & 23 & 10 \\
13 & 24 & 29 & 10 & 22 & 14 & 30 & 23 & 23 & 14 & 18 & 27 & 14 & 0 & 26 & 14 & 14 & 26 & 11 & 43 & 24 \\
14 & 28 & 31 & 18 & 32 & 29 & 24 & 21 & 24 & 31 & 17 & 11 & 29 & 28 & 0 & 48 & 25 & 11 & 13 & 27 & 23 \\
15 & 31 & 35 & 25 & 11 & 13 & 27 & 23 & 16 & 28 & 20 & 14 & 13 & 18 & 34 & 0 & 17 & 26 & 14 & 14 & 26 \\
16 & 19 & 28 & 23 & 14 & 21 & 11 & 39 & 25 & 14 & 25 & 25 & 21 & 17 & 24 & 29 & 0 & 28 & 25 & 24 & 15 \\
17 & 23 & 24 & 17 & 26 & 14 & 14 & 26 & 11 & 43 & 38 & 13 & 14 & 20 & 11 & 28 & 25 & 0 & 24 & 31 & 20 \\
18 & 17 & 19 & 20 & 29 & 21 & 25 & 35 & 27 & 17 & 13 & 20 & 21 & 25 & 19 & 18 & 11 & 23 & 0 & 11 & 13 \\
19 & 14 & 23 & 15 & 17 & 20 & 13 & 23 & 28 & 23 & 34 & 51 & 20 & 38 & 23 & 17 & 27 & 39 & 21 & 0 & 26 \\
20 & 24 & 30 & 30 & 19 & 27 & 18 & 26 & 20 & 18 & 21 & 24 & 13 & 24 & 24 & 20 & 28 & 26 & 17 & 31 & 0 \\
\hline
\end{tabular}

Traffic data for the disaster risk areas are presented in Figure 5. The values in circles indicate node numbers and the values below links indicate link numbers. The values in brackets indicate the length, capacity, and free flow impedance of links, whose format is $\left(l_{a}, c_{a}, t_{a}^{0}\right)$.

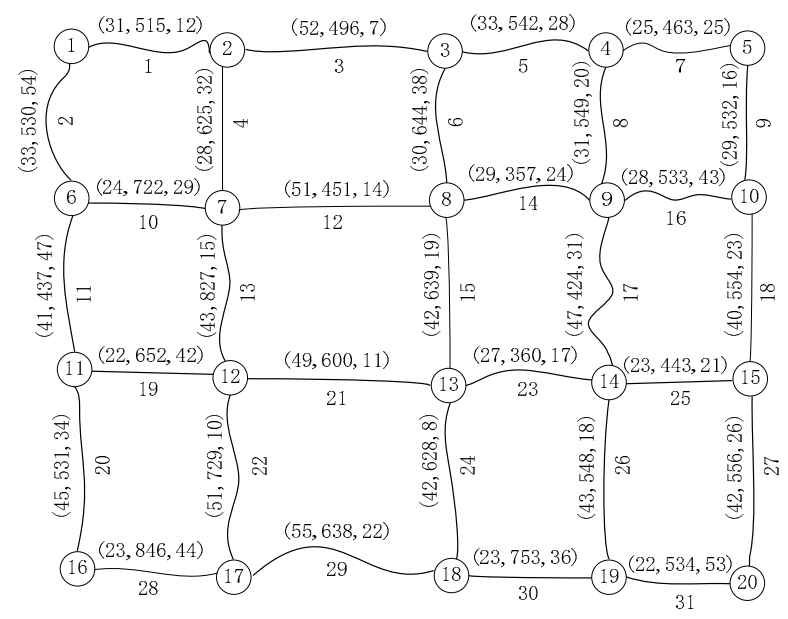

Figure 5. Traffic data in the disaster risk area.

Tables 3-5 present the data of possible disaster scenarios in such an urban area under four possible disaster scenarios $\left(\omega_{1}, \omega_{2}, \omega_{3}, \omega_{4}\right)$ and their occurrence probabilities. In the tables, $\mu_{\omega}$ is the travel demand matrix multiplier under disaster scenario $\omega$, which applies in Equation (13); 1 and 0 represent the connectivity states of links 1-31 under possible disaster scenarios without pre-disaster retrofit, with 1 indicating that the link is not subject to such disaster and 0 indicating that the link is affected under such disaster scenario and will be completely damaged without pre-disaster retrofit.

This paper proposes to subdivide retrofits into five levels, with different unit length costs. According to prior experience, as shown in Table 6, the unit length costs of medium retrofit, overhaul retrofit, and reconstruction are, respectively, about 3-4, 10, and 100-400 times those of minor retrofit. The unit length costs of restoration are slightly less than the costs of reconstruction, which also reflects the necessity for pre-disaster retrofit from a cost-saving perspective. 
Table 3. Occurrence probabilities of disaster scenarios and damage states of links 1-10.

\begin{tabular}{|c|c|c|c|c|c|c|c|c|c|c|c|c|}
\hline $\begin{array}{l}\text { Disaster } \\
\text { Scenario }\end{array}$ & $\begin{array}{l}\text { Occurrence } \\
\text { Probability }\end{array}$ & $\mu_{\omega}$ & $\begin{array}{c}\text { Link } \\
1\end{array}$ & $\begin{array}{c}\text { Link } \\
2\end{array}$ & $\begin{array}{c}\text { Link } \\
3\end{array}$ & $\begin{array}{c}\text { Link } \\
4\end{array}$ & $\begin{array}{c}\text { Link } \\
5\end{array}$ & $\begin{array}{c}\text { Link } \\
6\end{array}$ & $\begin{array}{c}\text { Link } \\
7\end{array}$ & $\begin{array}{c}\text { Link } \\
8\end{array}$ & $\begin{array}{c}\text { Link } \\
9\end{array}$ & $\begin{array}{c}\text { Link } \\
10\end{array}$ \\
\hline$\omega_{1}$ & 0.2 & 0.6 & 0 & 0 & 1 & 0 & 1 & 0 & 1 & 0 & 1 & 1 \\
\hline$\omega_{2}$ & 0.3 & 0.4 & 1 & 0 & 1 & 0 & 1 & 1 & 1 & 0 & 1 & 0 \\
\hline$\omega_{3}$ & 0.2 & 0.5 & 1 & 0 & 1 & 0 & 1 & 1 & 0 & 0 & 1 & 0 \\
\hline$\omega_{4}$ & 0.3 & 0.3 & 1 & 1 & 0 & 1 & 0 & 1 & 0 & 1 & 0 & 1 \\
\hline
\end{tabular}

Table 4. Occurrence probabilities of disaster scenarios and damage states of links 11-20.

\begin{tabular}{ccccccccccccc}
\hline $\begin{array}{c}\text { Disaster } \\
\text { Scenario }\end{array}$ & $\begin{array}{c}\text { Occurrence } \\
\text { Probability }\end{array}$ & $\boldsymbol{\mu}_{\boldsymbol{\omega}}$ & $\begin{array}{c}\text { Link } \\
\mathbf{1 1}\end{array}$ & $\begin{array}{c}\text { Link } \\
\mathbf{1 2}\end{array}$ & $\begin{array}{c}\text { Link } \\
\mathbf{1 3}\end{array}$ & $\begin{array}{c}\text { Link } \\
\mathbf{1 4}\end{array}$ & $\begin{array}{c}\text { Link } \\
\mathbf{1 5}\end{array}$ & $\begin{array}{c}\text { Link } \\
\mathbf{1 6}\end{array}$ & $\begin{array}{c}\text { Link } \\
\mathbf{1 7}\end{array}$ & $\begin{array}{c}\text { Link } \\
\mathbf{1 8}\end{array}$ & $\begin{array}{c}\text { Link } \\
\mathbf{1 9}\end{array}$ & $\begin{array}{c}\text { Link } \\
\mathbf{2 0}\end{array}$ \\
\hline$\omega_{1}$ & 0.2 & 0.6 & 1 & 0 & 1 & 0 & 0 & 0 & 1 & 0 & 1 & 1 \\
$\omega_{2}$ & 0.3 & 0.4 & 1 & 1 & 0 & 1 & 1 & 0 & 1 & 0 & 1 & 0 \\
$\omega_{3}$ & 0.2 & 0.5 & 1 & 0 & 1 & 0 & 1 & 1 & 0 & 0 & 1 & 1 \\
$\omega_{4}$ & 0.3 & 0.3 & 0 & 1 & 0 & 1 & 0 & 1 & 0 & 1 & 0 & 1 \\
\hline
\end{tabular}

Table 5. Occurrence probabilities of disaster scenarios and damage states of links 21-31.

\begin{tabular}{ccccccccccccccc}
\hline $\begin{array}{c}\text { Disaster } \\
\text { Scenario }\end{array}$ & $\begin{array}{c}\text { Occurrence } \\
\text { Probability }\end{array}$ & $\boldsymbol{\mu}_{\boldsymbol{\omega}}$ & $\begin{array}{c}\text { Link } \\
\mathbf{2 1}\end{array}$ & $\begin{array}{c}\text { Link } \\
\mathbf{2 2}\end{array}$ & $\begin{array}{c}\text { Link } \\
\mathbf{2 3}\end{array}$ & $\begin{array}{c}\text { Link } \\
\mathbf{2 4}\end{array}$ & $\begin{array}{c}\text { Link } \\
\mathbf{2 5}\end{array}$ & $\begin{array}{c}\text { Link } \\
\mathbf{2 6}\end{array}$ & $\begin{array}{c}\text { Link } \\
\mathbf{2 7}\end{array}$ & $\begin{array}{c}\text { Link } \\
\mathbf{2 8}\end{array}$ & $\begin{array}{c}\text { Link } \\
\mathbf{2 9}\end{array}$ & $\begin{array}{c}\text { Link } \\
\mathbf{3 0}\end{array}$ & $\begin{array}{c}\text { Link } \\
\mathbf{3 1}\end{array}$ \\
\hline$\omega_{1}$ & 0.2 & 0.6 & 0 & 1 & 1 & 1 & 1 & 0 & 1 & 0 & 1 & 1 & 1 \\
$\omega_{2}$ & 0.3 & 0.4 & 1 & 0 & 1 & 0 & 1 & 1 & 1 & 0 & 0 & 0 & 1 \\
$\omega_{3}$ & 0.2 & 0.5 & 0 & 0 & 0 & 0 & 1 & 1 & 0 & 0 & 1 & 0 & 1 \\
$\omega_{4}$ & 0.3 & 0.3 & 1 & 1 & 0 & 1 & 0 & 1 & 0 & 1 & 0 & 1 & 0 \\
\hline
\end{tabular}

Table 6. Unit length cost of retrofitting (five retrofit projects) and maintenance [42].

\begin{tabular}{|c|c|c|c|c|c|}
\hline \multirow{2}{*}{$\begin{array}{l}\text { Link } \\
\text { Number }\end{array}$} & \multicolumn{4}{|c|}{ Retrofit Cost of Unit Length $\sigma_{a}$} & \multirow{2}{*}{$\begin{array}{l}\text { Restoration Cost } \\
\text { of Unit Length } \tau_{a}\end{array}$} \\
\hline & $\begin{array}{c}\text { Minor Retrofit } \\
\quad(n=1)\end{array}$ & $\begin{array}{l}\text { Medium Retrofit } \\
\qquad(n=2)\end{array}$ & $\begin{array}{l}\text { Overhaul Retrofit } \\
\qquad(n=3)\end{array}$ & $\begin{array}{c}\text { Reconstruction } \\
(n=4)\end{array}$ & \\
\hline 1 & 0.13 & 0.43 & 1.3 & 21 & 6.3 \\
\hline 2 & 0.27 & 0.97 & 2.7 & 33 & 13.4 \\
\hline 3 & 0.18 & 0.64 & 1.8 & 26 & 8.1 \\
\hline 4 & 0.22 & 0.73 & 2.2 & 31 & 11.8 \\
\hline 5 & 0.25 & 0.81 & 2.5 & 29 & 9.3 \\
\hline 6 & 0.26 & 0.87 & 2.6 & 41 & 17.5 \\
\hline 7 & 0.32 & 1.12 & 3.2 & 45 & 19.6 \\
\hline 8 & 0.15 & 0.46 & 1.5 & 17 & 4.7 \\
\hline 9 & 0.45 & 1.61 & 4.5 & 53 & 21.4 \\
\hline 10 & 0.23 & 0.85 & 2.3 & 27 & 10.2 \\
\hline 11 & 0.12 & 0.44 & 1.2 & 15 & 4.8 \\
\hline 12 & 0.34 & 1.15 & 3.4 & 47 & 19.5 \\
\hline 13 & 0.23 & 0.72 & 2.3 & 34 & 11.4 \\
\hline 14 & 0.16 & 0.54 & 1.6 & 26 & 9.8 \\
\hline 15 & 0.28 & 1.03 & 2.8 & 47 & 15.6 \\
\hline 16 & 0.24 & 0.81 & 2.4 & 38 & 12.8 \\
\hline 17 & 0.15 & 0.58 & 1.5 & 33 & 10.7 \\
\hline 18 & 0.29 & 0.94 & 2.9 & 76 & 24.3 \\
\hline 19 & 0.32 & 1.12 & 3.2 & 47 & 15.9 \\
\hline 20 & 0.15 & 0.5 & 1.5 & 31 & 10.5 \\
\hline 21 & 0.45 & 1.44 & 4.5 & 52 & 14.8 \\
\hline 22 & 0.27 & 0.96 & 2.7 & 63 & 20.6 \\
\hline 23 & 0.12 & 0.38 & 1.2 & 16 & 5.3 \\
\hline 24 & 0.34 & 1.18 & 3.4 & 48 & 16.5 \\
\hline 25 & 0.19 & 0.63 & 1.9 & 27 & 8.4 \\
\hline 26 & 0.27 & 0.97 & 2.7 & 81 & 25.5 \\
\hline 27 & 0.18 & 0.56 & 1.8 & 41 & 14.6 \\
\hline 28 & 0.26 & 0.87 & 2.6 & 37 & 13.2 \\
\hline 29 & 0.18 & 0.59 & 1.8 & 22 & 8.7 \\
\hline 30 & 0.21 & 0.77 & 2.1 & 34 & 11.4 \\
\hline 31 & 0.27 & 0.91 & 2.7 & 43 & 14.2 \\
\hline
\end{tabular}


The calculation of the link impedances uses the BPR function:

$$
t_{a}\left(x_{a}, c_{a}\right)=t_{a}^{0}\left(1+k_{1} \cdot\left(\frac{x_{a}}{c_{a}}\right)^{k_{2}}\right)
$$

where $t_{a}^{0}$ is the free flow impedance of link $a$, and $k_{1}, k_{2}$ are constants, with $k_{1}=0.15, k_{2}=4.0$.

Set the budget ceiling of pre-disaster retrofit $\varepsilon=5500$ and the time reliability coefficient $\gamma_{t}=0.8$. Set the initial temperature of the SA algorithm $t_{0}=5000$, temperature drop ratio $\lambda=0.9$, iteration limit number at the same temperature $L=100$, terminal temperature $t_{f}=0.01$, and acceptance probability of the worst solution $p=0.65$.

In this paper, a method based on the simulated annealing algorithm and Frank-Wolfe algorithm is proposed. The model is calculated by MATLAB software and the pre-disaster retrofit decision plan in this case is obtained, as well as the cost component.

The pre-disaster retrofit decision plan is as follows:

$$
\bar{Y}=[1,3,3,0,1,1,3,0,1,3,3,0,3,1,4,0,2,2,2,3,1,3,2,0,0,3,2,0,1,3,0] .
$$

The pre-disaster retrofit decision plan $\bar{Y}$ obtained by method describes the retrofit levels of links. The total cost is $S=4819.73$, including pre-disaster retrofit cost and expected post-disaster emergency restoration cost.

The best results are shown in Table 7. As we can see, the pre-disaster retrofit cost is 3002.6 when the transportation system in this case is retrofitted as the optimal plan. Thirteen links will be destroyed under disaster scenario $\omega_{1}$ while 7028.2 will be spent to restore them. If the transportation system were retrofitted in advance, only five links would be destroyed in the same disaster scenario. The sum of pre-disaster retrofit cost and post-disaster restoration cost will be far less than the restoration cost without retrofit. The situation under disaster scenarios $\omega_{2}, \omega_{3}$, and $\omega_{4}$ also confirm this conclusion, which reflects the necessity for pre-disaster retrofit whether from the engineering or economic perspective.

\begin{tabular}{|c|c|c|c|c|c|}
\hline $\begin{array}{l}\text { Disaster } \\
\text { Scenario }\end{array}$ & $\begin{array}{c}\text { Retrofit } \\
\text { Cost }\end{array}$ & $\begin{array}{c}\text { Restoration } \\
\text { Cost }\end{array}$ & $\begin{array}{c}\text { Destroyed Links } \\
\text { (Retrofitted as } \\
\text { Optimal Plan) }\end{array}$ & $\begin{array}{l}\text { Destroyed Links } \\
\text { (not Retrofitted as } \\
\text { Optimal Plan) }\end{array}$ & $\begin{array}{l}\text { Restoration Cost } \\
\text { (without Retrofit) }\end{array}$ \\
\hline$\omega_{1}$ & \multirow{4}{*}{3002.6} & 2132.6 & $4,8,12,16,28$ & $\begin{array}{c}1,2,4,6,8,12,14,15 \\
16,18,21,26,28\end{array}$ & 7028.2 \\
\hline$\omega_{2}$ & & 1831.1 & $4,8,16,24,28$ & $\begin{array}{l}2,4,8,10,13,16,18 \\
20,22,24,28,29,30\end{array}$ & 6244.1 \\
\hline$\omega_{3}$ & & 2467.2 & $4,8,12,24,28$ & $\begin{array}{c}2,4,7,8,10,12,14,17,18 \\
21,22,23,24,27,28,30\end{array}$ & 8197.6 \\
\hline$\omega_{4}$ & & 505.6 & 25,31 & $\begin{array}{c}3,5,7,9,11,13,15,17 \\
19,23,25,27,29,31\end{array}$ & 5774 \\
\hline
\end{tabular}

Table 7. Case results.

This paper analyzes whether or not the pre-disaster retrofit decision plan obtained by the bi-level stochastic programming model satisfies all the constraints.

As we can see in Table 7, the pre-disaster retrofit cost is 3002.6, which is less than the budget ceiling, in this case 5500. Thus, Equation (6) is illustrated and the retrofit decision plan satisfies the budget constraints. Moreover, the total cost spent in this case while the transportation system was retrofitted as the pre-disaster retrofit decision plan decreases $26.9 \%, 22.6 \%, 33.3 \%$, and $39.2 \%$ of that without retrofit in disaster scenarios $\omega_{1}, \omega_{2}, \omega_{3}$, and $\omega_{4}$, which illustrates the necessity of pre-disaster retrofit for cost saving.

For post-disaster connectivity of the transportation system, it is not realistic to verify all $O D$ pairs because of the large scale in this case. OD pairs $(2,10),(13,17)$, and $(19,20)$ are selected for analysis. 
To satisfy connectivity constraints, the pre-disaster retrofit decision plan is supposed to ensure the accessibility between $O D$ pairs, i.e., that there exists at least one valid path between any $O D$ pair under possible disaster scenarios. Combined with Table 7, Table 8 lists connective paths (represented by node numbers) between $O D$ pairs $(2,10),(13,17)$, and $(19,20)$ in disaster scenarios $\omega_{1}, \omega_{2}, \omega_{3}$, and $\omega_{4}$. There are other connective paths between these $O D$ pairs that are not listed in the table. Thus, Equation (7) is illustrated and connectivity constraints are satisfied by the retrofit decision plan.

Table 8. Connectivity constraints.

\begin{tabular}{cccc}
\hline Disaster Scenario & $\begin{array}{c}\text { Connective Path between } \\
\text { OD Pair (2,10) }\end{array}$ & $\begin{array}{c}\text { Connective Path between } \\
\text { OD Pair (17,13) }\end{array}$ & $\begin{array}{c}\text { Connective Path between } \\
\text { OD Pair }(\mathbf{1 9 , 2 0 )}\end{array}$ \\
\hline$\omega_{1}$ & $2 \rightarrow 3 \rightarrow 4 \rightarrow 5 \rightarrow 10$ & $17 \rightarrow 18 \rightarrow 13$ & $19 \rightarrow 20$ \\
$\omega_{2}$ & $2 \rightarrow 3 \rightarrow 4 \rightarrow 5 \rightarrow 10$ & $17 \rightarrow 12 \rightarrow 13$ & $19 \rightarrow 20$ \\
$\omega_{3}$ & $2 \rightarrow 3 \rightarrow 4 \rightarrow 5 \rightarrow 10$ & $17 \rightarrow 12 \rightarrow 13$ & $19 \rightarrow 20$ \\
$\omega_{4}$ & $2 \rightarrow 3 \rightarrow 4 \rightarrow 5 \rightarrow 10$ & $17 \rightarrow 12 \rightarrow 13$ & $19 \rightarrow 14 \rightarrow 9 \rightarrow 10 \rightarrow 15 \rightarrow 20$ \\
\hline
\end{tabular}

Except for accessibility between $O D$ pairs, destruction rate of links $\Theta$ is also appropriate to evaluate system connectivity.

$$
\Theta=\frac{n_{\omega}}{n_{A}}
$$

$n_{\omega}$ is the number of destroyed link under disaster scenarios $\omega$ while $n_{A}$ is the number of links within the transportation system.

$n_{\omega}$ and $\Theta$ with or without retrofit in $\omega_{1}, \omega_{2}, \omega_{3}$, and $\omega_{4}$ are shown in Table 9. $n_{A}$ is 31 in this case. As we can see, the average of $\Theta$ can decrease $69.9 \%$ compared with retrofit before, which illustrates the retrofit effect of post-disaster connectivity state of links is obvious.

Table 9. Destruction rate of links.

\begin{tabular}{|c|c|c|c|c|c|c|}
\hline \multirow{2}{*}{$\begin{array}{l}\text { Disaster } \\
\text { Scenario }\end{array}$} & \multicolumn{2}{|c|}{ Without Retrofit } & \multicolumn{2}{|c|}{ Retrofitted as Optimal Plan } & \multirow{2}{*}{$\begin{array}{c}\text { The Reduction } \\
\text { of } \Theta\end{array}$} & \multirow{2}{*}{$\begin{array}{c}\text { The Average } \\
\text { Reduction of } \Theta\end{array}$} \\
\hline & $n_{\omega}$ & $\Theta$ & $n_{\omega}$ & $\Theta$ & & \\
\hline$\omega_{1}$ & 13 & 0.42 & 5 & 0.16 & $61.9 \%$ & \multirow{4}{*}{$69.9 \%$} \\
\hline$\omega_{2}$ & 13 & 0.42 & 5 & 0.16 & $61.9 \%$ & \\
\hline$\omega_{3}$ & 16 & 0.52 & 5 & 0.16 & $69.2 \%$ & \\
\hline$\omega_{4}$ & 14 & 0.45 & 2 & 0.06 & $86.7 \%$ & \\
\hline
\end{tabular}

To satisfy capacity constraints, it is necessary to ensure that links within the post-disaster transportation system have certain capacity. In other words, traffic flow in the link cannot exceed its post-disaster capacity. The ratios of traffic flows to capacities on links in four disaster scenarios are presented in Figure 6a-d. As shown in the figure, this paper defines the concept of forward link as its node number of origin being smaller than that of destination; otherwise, it is a reverse link.

If the link is completely destroyed (i.e., disconnected), it will not be passable. Its capacity is reduced to 0 and the flow on the link is 0 as well. Equation (10) is tenable at this point, and the ratios in the figures are in line with $\frac{x}{c}=1$. Except for destroyed links, other links either are not affected by such disaster or are still connective, and their capacities either vary or stay the same as before, and their flows may vary but will not be 0 . As shown in Figure $6 a-d$, for all links, the ratio of flow to capacity is no more than 1. Thus, Equation (10) is proved and capacity constraints are satisfied by the retrofit decision plan.

It is not realistic to verify travel time reliability constraints of all $O D$ pairs because of the large scale in this case. $O D$ pairs $(17,13)$ and $(19,20)$ are chosen to represent all $O D$ pairs to verify travel time reliability constraints. 


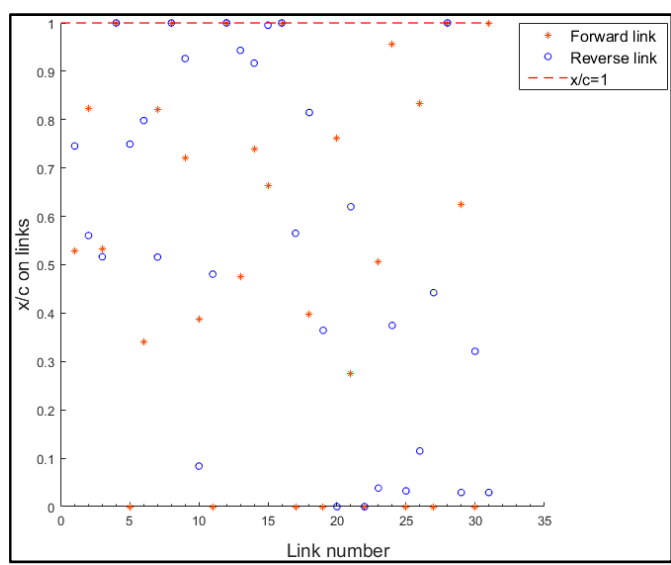

(a) $\omega_{1}$

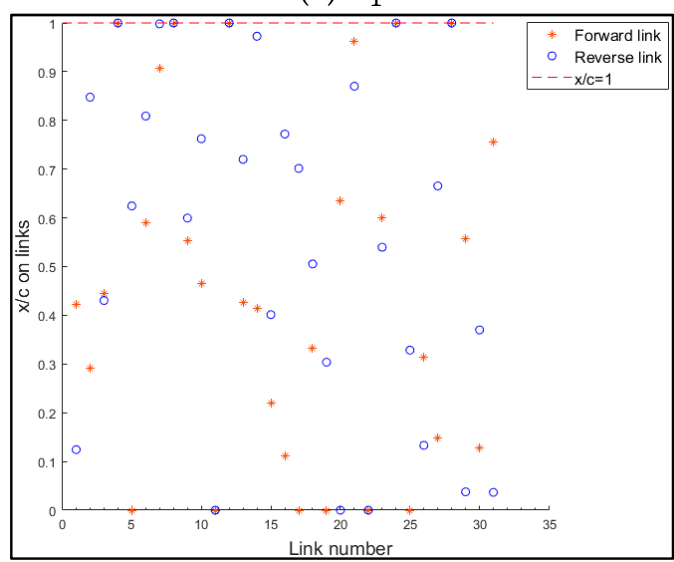

(c) $\omega_{3}$

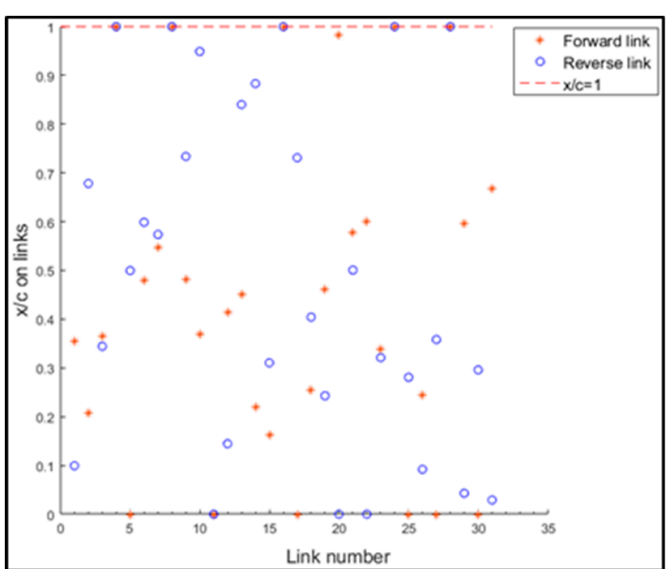

(b) $\omega_{2}$

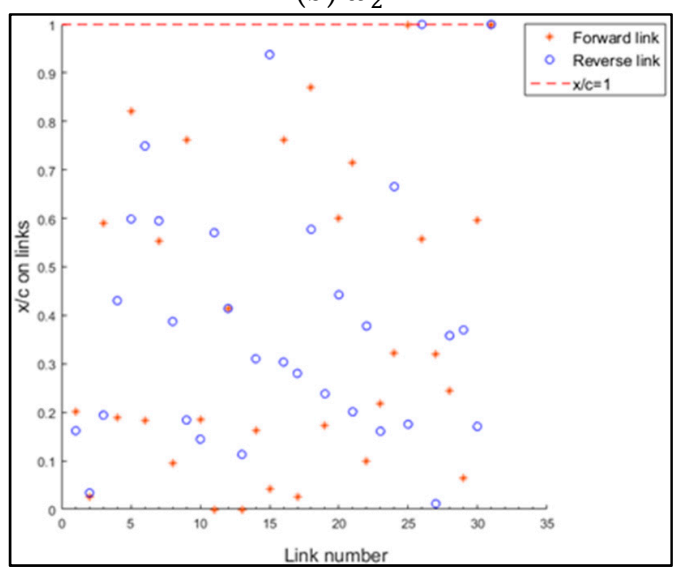

(d) $\omega_{4}$

Figure 6. $x / c$ of links under disaster scenarios $\left(\omega_{1}, \omega_{2}, \omega_{3}, \omega_{4}\right)$.

Regarding the above assumption, drivers will choose the minimum impedance path between origin and destination. If the link is disconnected, travel time on the link is $\infty$. Also, the link must not be on the path connecting the $O D$ pair, so $\delta_{i j}^{a k}$ is 0 . Equation (8) is tenable at this point. As shown in Table 10, the ratios of travel time for the minimum impedance path of post-disaster to pre-disaster between $O D$ pairs $(17,13)$ and $(19,20)$ are less than the time reliability coefficient $\gamma_{t} 0.8$. Thus, Equation $(8)$ is proved and the travel time reliability constraints are satisfied by the retrofit decision plan.

Table 10. Travel time reliability constraints.

\begin{tabular}{ccccc}
\hline $\begin{array}{c}\text { Disaster } \\
\text { Scenario }\end{array}$ & $\begin{array}{c}\text { Post-Disaster Minimum Impedance } \\
\text { Path between OD Pair (17,13) }\end{array}$ & $\begin{array}{c}\text { Travel } \\
\text { Time }\end{array}$ & $\begin{array}{c}\text { Pre-Disaster Minimum Impedance } \\
\text { Path between OD Pair (17,13) }\end{array}$ & $\begin{array}{c}\text { Travel } \\
\text { Time }\end{array}$ \\
\hline$\omega_{1}$ & $17 \rightarrow 18 \rightarrow 13$ & 66.25 & & \\
$\omega_{2}$ & $17 \rightarrow 12 \rightarrow 13$ & 60.15 & $17 \rightarrow 12 \rightarrow 13$ & 82.90 \\
$\omega_{3}$ & $17 \rightarrow 12 \rightarrow 13$ & 65.08 & & Travel \\
$\omega_{4}$ & $17 \rightarrow 12 \rightarrow 13$ & 61.00 & & Time \\
\hline Disaster & Post-Disaster Minimum Impedance & Travel & Pre-Disaster Minimum Impedance \\
Scenario & Path between OD Pair (19,20) & Time & Path between OD Pair (19,20) & 153.63 \\
\hline$\omega_{1}$ & $19 \rightarrow 20$ & 60.95 & & 19 $\rightarrow 20$ \\
$\omega_{2}$ & $19 \rightarrow 20$ & 54.57 & & \\
$\omega_{3}$ & $19 \rightarrow 20$ & 55.59 & & \\
$\omega_{4}$ & $19 \rightarrow 14 \rightarrow 9 \rightarrow 10 \rightarrow 15 \rightarrow 20$ & 114.03 & &
\end{tabular}

Budget, connectivity, travel time reliability, capacity, and retrofit level constraints are shown in Table 11. All constraints are satisfied in this case according to the above analysis. Therefore, 
the pre-disaster retrofit decision plans for transportation systems in urban areas proposed in this paper are feasible.

Table 11. Summary of constraints.

\begin{tabular}{|c|c|c|}
\hline Equation & Constraints & Conditions to Satisfy Constraints \\
\hline (6) & Budget & Pre-disaster retrofit cost does not exceed budget ceiling. \\
\hline (7) & Connectivity & $\begin{array}{l}\text { There exists at least one connective path between any } O D \text { pair under } \\
\text { possible disaster scenarios. }\end{array}$ \\
\hline$(8)$ & Travel time reliability & $\begin{array}{c}\text { Ratios of travel time on minimum impedance path of post-disaster to } \\
\text { pre-disaster between } O D \text { pairs are less than the time reliability } \\
\text { coefficient } \gamma_{t} .\end{array}$ \\
\hline$(10)$ & Capacity & Traffic flow on the link does not exceed its post-disaster capacity. \\
\hline$(11)$ & Retrofit level & Variables in retrofit decision plan are nonnegative integers from 0 to 4. \\
\hline
\end{tabular}

\section{Conclusions and Future Directions}

For disaster risk reduction and sustainable development of transportation systems in urban areas, this paper proposes a bi-level stochastic programming model for the pre-disaster retrofit problem. The simulated annealing algorithm and Frank-Wolfe algorithm are used to solve the problem. The transportation system of a mid-size city in China with disaster risks is taken as a study case for analysis. The optimization results are feasible. Computational efficiency and convergence are also great. The proposed method not only can help policymakers to analyze and optimize decision-making but also has certain reference significance for guiding the restoration and reconstruction of post-disaster transportation systems. Moreover, disaster risk reduction and resilience of transportation systems are multidisciplinary concepts, and it is important to discuss methods and people suitable for developing the model. First, researchers in the field of traffic and civil engineering are the main forces for developing the model and solving it by algorithm. They may be more inclined to be on an academic level. Second, road engineers, road maintenance staff, and even technical workers play vital roles because of their rich practical experience, and the model will be more practical with their help. Third, policymakers in transportation departments could give valuable suggestions from a macro perspective. Last but not least, disaster researchers are needed to study disasters, including their types, characteristics, and development trends. They can also collect disaster data, look for regular disaster, and try to predict disaster occurrence. Their work is greatly helpful for improving the model.

The existing research mostly defined the retrofit states of links as a $0-1$ variable, which only considers whether to retrofit or not. However, in reality, due to factors such as retrofit cost, it is not realistic to retrofit each link to the highest degree. This paper proposes to subdivide retrofits into five levels, which increases the realistic feasibility of the model and provides more possibilities for pre-disaster retrofit decision plans.

The case study indicates that the effect of a retrofitted transportation system is obvious, and its anti-destructive ability and post-disaster recovery rate are greatly improved, all of which reflects its resilience. In the same disaster scenario, the retrofitted transportation system has better performance than the non-retrofitted one in terms of system connectivity, post-disaster link capacity, and travel time reliability. From the economic viewpoint, the total pre-disaster retrofit costs and post-disaster restoration costs after retrofitting are far less than the restoration costs without pre-disaster retrofit, which illustrates the significance of pre-disaster retrofitting for cost saving. Thus, pre-disaster retrofit decisions for sustainable transportation systems in urban areas are helpful for effective risk management, which not only is vital in engineering, such as road retrofitting and restoration, but also reduces economic costs.

There are several future directions to further develop the present work. The study has limitations and needs to be further developed due to the lack of data related to disasters. Moreover, the retrofit effect of the model could be extended by considering more factors such as robustness. 
Author Contributions: Y.Z. wrote the main manuscript text, built the model and conducted the experiment; J.Q. analyzed the data; Q.J. contributed to the introduction and revised the paper. All the authors have reviewed the manuscript.

Funding: This research was supported by the Natural Science Foundation of China (No. 71101155) and Natural Science Foundation of Hunan Province (No. 2015JJ2184).

Acknowledgments: The authors would like to acknowledge all experts' contributions in the building of the model and the solution of the algorithm in this study.

Conflicts of Interest: The authors declare no conflict of interest.

\section{References}

1. Usuzawa, M.; Telan, E.O.; Kawano, R.; Dizon, C.S.; Alisjahbana, B.; Ashino, Y. Awareness of disaster reduction frameworks and risk perception of natural disaster: a questionnaire survey among philippine and indonesian health care personnel and public health students. Tohoku J. Exp. Med. 2014, 233, 43-48. [CrossRef] [PubMed]

2. Satake, K. Advances in earthquake and tsunami sciences and disaster risk reduction since the 2004 Indian ocean tsunami. Geosci. Lett. 2014, 1, 15. [CrossRef]

3. Haghi, M.; Ghomi, S.M.T.F.; Jolai, F. Developing a robust multi-objective model for pre/post disaster times under uncertainty in demand and resource. J. Clean. Prod. 2017, 154, 188-202. [CrossRef]

4. Sadik, M.S.; Nakagawa, H.; Rahman, R. A Study on Cyclone Aila Recovery in Koyra, Bangladesh: Evaluating the Inclusiveness of Recovery with Respect to Predisaster Vulnerability Reduction. Int. J. Disaster Risk Sci. 2018, 9, 28-43. [CrossRef]

5. Dong, X. Post-Disaster Recovery Planning and Sustainable Development-A Lesson from the Wenchuan Earthquake, China, 2008. Msater's Thesis, University of Illinois at Urbana-Champaign, Champaign, IL, USA, 22 May 2012.

6. Tuzun, A.D.; Ozdamar, L. A mathematical model for post-disaster road restoration: Enabling accessibility and evacuation. Transp. Res. Part E Logist. Transp. Rev. 2014, 61, 56-67. [CrossRef]

7. Zhao, R.; Zhong, S.; He, A. Disaster Impact, National Aid, and Economic Growth: Evidence from the 2008 Wenchuan Earthquake. Sustainability 2018, 10, 4409. [CrossRef]

8. Xiang, M.; Zhao, W.; Chen, J. A Comparison of Different Reconstruction Modes and Adaptive Evaluation Systems for Community Recovery Following the Wenchuan Earthquake. Sustainability 2018, 10, 4115. [CrossRef]

9. Bodoque, J.M.; Amérigo, M.; Díez-Herrero, A. Improvement of resilience of urban areas by integrating social perception in flash-flood risk management. J. Hydrol. 2016, 541, 665-676. [CrossRef]

10. Alexander, D.E. Resilience and disaster risk reduction: an etymological journey. Nat. Hazards Earth Syst. Sci. 2013, 13, 2707-2716. [CrossRef]

11. Zhang, W.; Wang, N. Resilience-based risk mitigation for road networks. Struct. Saf. 2016, 62, 57-65. [CrossRef]

12. Liu, C.; Fan, Y.; Ordóñez, F. A two-stage stochastic programming model for transportation network protection. Comput. Oper. Res. 2009, 36, 1582-1590. [CrossRef]

13. Du, L.; Peeta, S. A Stochastic Optimization Model to Reduce Expected Post-Disaster Response Time Through Pre-Disaster Investment Decisions. Netw. Spat. Econ. 2014, 14, 271-295. [CrossRef]

14. Chu, J.C.; Chen, S.C. Optimization of Transportation-Infrastructure-System Protection Considering Weighted Connectivity Reliability. J. Infrastruct. Syst. 2016, 22, 04015008. [CrossRef]

15. Bin, L.I. Transportation Network Reconstruction for Natural Disasters in Emergency Phase Based on Connectivity Reliability. Comput. Commun. 2008, 2963-2968. [CrossRef]

16. Kuang, A.; Tang, Z.; Shan, L. Road Network Capacity Reliability Considering Travel Time Reliability. Procedia Soc. Behav. Sci. 2013, 96, 1818-1827. [CrossRef]

17. Leng, J.Q.; Zhang, Y.P.; Zhang, Q. Integrated reliability or travel time and capacity or urban road network under ice and snowfall conditions. J. Cent. South Univ. 2010, 17, 419-424. [CrossRef]

18. Yücel, E.; Salman, F.S.; Arşik, I. Improving Post-Disaster Road Network Accessibility by Strengthening Links against Failures. Eur. J. Oper. Res. 2018, 269. [CrossRef] 
19. Loredana, A.; Roberto, C.; Francesco, D.P. Social Perception of Geo-Hydrological Risk in the Context of Urban Disaster Risk Reduction: A Comparison between Experts and Population in an Area of Southern Italy. Sustainability 2019, 11, 2061. [CrossRef]

20. Jamieson, T.; Belle, D.A.V. How Development Affects News Media Coverage of Earthquakes: Implications for Disaster Risk Reduction in Observing Communities. Sustainability 2019, 11, 1970. [CrossRef]

21. Zhou, Y.; Banerjee, S.; Shinozuka, M. Socio-economic effect of seismic retrofit of bridges for highway transportation networks: a pilot study. Struct. Infrastruct. Eng. 2010, 6, 145-157. [CrossRef]

22. Pradhananga, R.; Mutlu, F.; Pokharel, S.; José, H.-V.; Seth, D. An integrated resource allocation and distribution model for pre-disaster planning. Comput. Ind. Eng. 2016, 91, 229-238. [CrossRef]

23. Fan, Y.; Liu, C. Solving Stochastic Transportation Network Protection Problems Using the Progressive Hedging-based Method. Netw. Spat. Econ. 2010, 10, 193-208. [CrossRef]

24. Unjoh, S.; Terayama, T.; Adachi, Y. Seismic retrofit of existing highway bridges in Japan. Cem. Concr. Compos. 2000, 22, 1-16. [CrossRef]

25. Peeta, S.; Salman, F.S.; Gunnec, D. Pre-disaster investment decisions for strengthening a highway network. Comput. Oper. Res. 2010, 37, 1708-1719. [CrossRef]

26. Yan, Y.; Hong, L.; He, X. Pre-disaster investment decisions for strengthening the Chinese railway system under earthquakes. Transp. Res. Part E Logist. Transp. Rev. 2017, 105, 39-59. [CrossRef]

27. Rokneddin, K.; Ghosh, J.; Dueñas-Osorio, L. Bridge retrofit prioritisation for ageing transportation networks subject to seismic hazards. Struct. Infrastruct. Eng. 2013, 9, 1050-1066. [CrossRef]

28. Kim, Y.S. Seismic Loss Assessment and Mitigation of Critical Urban Infrastructure Systems. Ph. D. Thesis, University of Illinois at Urbana-Champaign, Champaign, IL, USA, 2008.

29. Dong, Y.; Frangopol, D.M.; Saydam, D. Pre-Earthquake Multi-Objective Probabilistic Retrofit Optimization of Bridge Networks Based on Sustainability. J. Bridge Eng. 2014, 19, 04014018. [CrossRef]

30. Zhang, L.X.; Qin, J.; He, Y.X. Network-level optimization method for road network maintenance programming based on network efficiency. J. Cent. South Univ. 2015, 22, 4882-4889. [CrossRef]

31. Nagae, T.; Fujihara, T.; Asakura, Y. Anti-seismic reinforcement strategy for an urban road network. Transp. Res. Part A 2012, 46, 813-827. [CrossRef]

32. Zhejiang Highway Administration. Technical Specifications of Restoration for Highway; Communications Press: Zhejiang, China, 2009; Available online: http://www.chts.cn/files/20180129/0b049eb6-55a0-4d62-8c91d64a7c455303 (accessed on 18 July 2018).

33. Chen, W. Study on the Ordinary Cement Concrete Pavement Using Performance Evaluation and Restoration Repair Technology. Ph.D. Thesis, Changsha University of Science \& Technology, Changsha, China, 2013. (In Chinese)

34. Mu, A.D. Optimal Path Analysis and Evaluation of Road Network Resilience after Earthquake. Ph.D. Thesis, China Earthquake Administration, Institute of Engineering Mechanics, Beijing, China, 2017. (In Chinese)

35. Niu, S.F. Research on Analysis and Evaluation and Techniques of Road Network Traffic Running Situation under Disaster Conditions. Ph.D. Thesis, Jilin University, Jilin, China, 2011. (In Chinese)

36. Chen, A.; Yang, H.; Hong, K.L. Capacity reliability of a road network: an assessment methodology and numerical results. Transp. Res. Part. B 2002, 36, 225-252. [CrossRef]

37. Fang, X.Q. Study on Evaluation Method of Transportation Elements Damaged in the Earthquake. Ph.D. Thesis, China Earthquake Administration, Institute of Engineering Mechanics, Beijing, China, 2007. (In Chinese)

38. Jiang, L.C.; Liu, J.P. Revised Simulated Annealing Algorithm. Inst. Geophys. Geomat. 2007, 4, 135-140.

39. Hwang, C.R. Simulated annealing: Theory and applications. Acta Appl. Math. 1988, 12, 108-111. [CrossRef]

40. Fukushima, M. A modified Frank-Wolfe algorithm for solving the traffic assignment problem. Transp. Res. Part B 1984, 18, 169-177. [CrossRef]

41. Qin, J.; Qu, W.X.; Wu, X.K. Differential Pricing Strategies of High Speed Railway Based on Prospect Theory: An Empirical Study from China. Sustainability 2019, 11, 3804. [CrossRef]

42. Yi, W.Z.; Zhang, H.Q. Compilation of Valuation Basis for Highway Restoration Works in Guangdong; Guangdong Highway Communications: Guangzhou, China, 2004; pp. 58-61. (In Chinese)

(C) 2019 by the authors. Licensee MDPI, Basel, Switzerland. This article is an open access article distributed under the terms and conditions of the Creative Commons Attribution (CC BY) license (http://creativecommons.org/licenses/by/4.0/). 